existing skill mix and the capacity of other health professionals to carry out tasks previously restricted to scarce and expensive professionals, such as doctors, must be examined. The model of multidisciplinary teamwork that has emerged in old age psychiatry potentially provides a means whereby the valuable experience of the several disciplines concerned can be applied to the widest possible range of those who need it. However, further evaluation is needed of the other important aspects of psychogeriatric assessment, and of the long term outcomes associated with this particular style of service.

We thank the members of the two community teams and their patients for their help and cooperation with this study. This study was funded by the Lewisham and North Southwark Health Authority and the Redwood Trust and received support from Research and Development for Psychiatry.

1 Øvretveit J. Essentials of multidisciplinary team organisation. Uxbridge: Brunel University, BIOSS, 1988.

2 McGrath, M. Multi-disciplinary teamwork. Aldershot: Avebury, 1991
3 Arie T, Jolley D. Making services work: organisation and style of psychogeriatric services. In: Levy R, Post F, eds. The psychiatry of late life. Oxford: Blackwell, 1982.

4 Jolley D, Arie T. Developments in psychogeriatric services. In: Arie T, ed. Recent advances in psychogeriatrics. Vol 2. London: Churchill Livingstone, 1992 .

5 Coles RJ, Von Abendorff R, Herzberg JL. The impact of a new community mental health team on an inner city psychogeriatric service. Int $\mathcal{f}$ Geriatric Psychiatry 1991;6:31-9.

6 Murphy E. Why teams succeed. In: Lindesay J, ed. Working out: setting up and running community psychogeriatric teams. London: Research and Development for Psychiatry, 1991 .

7 Gelhaar E. Service evaluation in old age psychiatry: using the general practitioner's view. Psychiatric Bulletin 1988;12:428-30.

8 Copeland JRM, Kelleher MJ, Kellett JM, Gourlay AJ, Gorland BJ, Fliess JL et al. A semi-structured interview for the assessment of diagnosis and mental et al. A semi-structured interview for the assessment of diagnosis and mental
state in the elderly: the geriatric mental state schedule: development and

reliability. Psychol Med 1976;6:439-49.
SPSS/PC+. Statistical package for the sacial

9 SPSS/PC+. Statistical package for the social sciences. Chicago: SPSS, 1986.

10 Spitznagel EL, Helzer JE. A proposed solution to the base-rate problem in the kappa statistic. Arch Gen Psychiatry 1985;42:725-8.

11 Mental Health Services Joint Training Group (Guy's and Lewisham Trust). Brian's first case: multidisciplinary assessment of mental health problems in the elderly. East Sussex: Outset Publishers, 1991

12 Lindesay J, ed. Working out: setting up and running community psychogeriatric teams. London: Research and Development for Psychiatry, 1991.

13 Brearley S. Leading for health: manpower. BMF 1992;304:832-4.
Department of

Epidemiology and Public Health, University of Leicester, Leicester Royal Infirmary, PO Box 65, Leicester LE2 7LX

Michael Clarke, professor of epidemiology

Elizabeth S Mason, research associate

David G Clayton, senior

lecturer in medical statistics

Department of Obstetrics and Gynaecology,

University of Leicester

John MacVicar, professor of

obstetrics and gynaecology

Correspondence to:

Professor Clarke.

$B M 7$ 1993;306:824-7

\title{
Evaluating perinatal mortality rates: effects of referral and case mix
}

\author{
Michael Clarke, Elizabeth S Mason, John MacVicar, David G Clayton
}

\section{Abstract \\ Objective-To evaluate perinatal mortality rates} as a method of auditing obstetric and neonatal care after account had been taken of transfer between hospitals during pregnancy and case mix.

Design-Case-control study of perinatal deaths.

Setting-Leicestershire health district.

Subjects-1179 singleton perinatal deaths and their selected live born controls among 114362 singleton births to women whose place of residence was Leicestershire during 1978-87.

Main outcome measure-Crude perinatal mortality rates and rates adjusted for case mix.

Results-An estimated 11701 of the 28750 women booked for delivery in general practitioner maternity units were transferred to consultant units during their pregnancy. These 11701 women had a high perinatal mortality rate $(16 \cdot 8 / 1000$ deliveries $)$. Perinatal mortality rates by place of booking showed little difference between general practitioner units $(8 \cdot 8 / 1000)$ and consultant units (9.3-11·7/1000). Perinatal mortality rates by place of delivery, however, showed substantial differences between general practitioner units $(3 \cdot 3 / 1000)$ and consultant units $(9 \cdot 4-12 \cdot 6 / 1000)$ because of the selective referral of high risk women from general practitioner units to consultant units. Adjustment for risk factors made little difference to the rates except when the subset of deaths due to immaturity was adjusted for birth weight.

Conclusion-Perinatal mortality rates should be adjusted for case mix and referral patterns to get a meaningful result. Even when this is done it is difficult to compare the effectiveness of hospital units with perinatal mortality rates because of the increasingly small subset of perinatal deaths that are amenable to medical intervention.

\section{Introduction}

Evaluation in obstetrics is well developed, and the confidential enquiry into maternal mortality serves as a model for other mortality reviews.' The House of Commons Social Services Committee, however, has recently repeated its recommendation, first made in
1980, that epidemiological reviews of perinatal mortality rates should also be established. ${ }^{2}$ The Department of Health has endorsed this by requiring regional health authorities to establish epidemiological surveys of all stillbirths and neonatal deaths. ${ }^{3}$ In addition obstetricians conduct audits of their services and health authorities attempt to make purchasing decisions using, among other things, data on perinatal mortality.

While we welcome the use of such reviews, it is important that appropriate comparisons are made so that correct conclusions are drawn from differing perinatal mortality rates. For example, how can the perinatal mortality rate of an affluent part of East Anglia, with its low incidence of congenital malformations, be compared with that of an inner city area in south Wales, where a higher incidence of congenital malformation is combined with social disadvantage?

Since the mid-1970s we have reviewed perinatal mortality rates in Leicestershire to describe the cause and number of perinatal deaths and to use this information to influence local services. This report describes the referral patterns of women during pregnancy and the effect this has on the interpretation of perinatal risk; compares crude perinatal mortality rates between different maternity units; shows how adjustment for case mix influences the initial rates; and suggests ways of making analyses of perinatal mortality rates more relevant for evaluating obstetric and neonatal care.

\section{Subjects and methods}

SAMPLE POPULATION

In 1981 the population of Leicestershire was 845000 , of whom about 60000 originated from the Indian subcontinent. The data below relate to the 1179 perinatal deaths that occurred in the 114362 singleton deliveries to women resident in Leicestershire during 1978-87 regardless of place of delivery.

\section{STUDY DESIGN}

We used a case-control design with cases defined as perinatal deaths occurring among women whose place of residence was Leicestershire. The control for 
each perinatal death was the next live birth born to a Leicestershire woman in the intended place of delivery of the baby who died perinatally. We collected data by reviewing case notes and interviewing the women.

We calculated standardised perinatal mortality rates for the delivery units by using logistic regression to estimate relative risks adjusted for confounding factors and then standardising these rates by multiplying by a constant chosen so that the standardised rate for all Leicestershire agreed with the crude observed rate. The confounding factors were patients' characteristics that had been shown to be predictive of increased perinatal risk. ${ }^{4}$ Maternal risk factors known at booking were age under 18 or over 35 ; primiparity or parity of more than three; being in manual or non-manual work; being less than $158 \mathrm{~cm}$ tall; attending antenatal care after 18 weeks' gestation; having diabetes; being a smoker; being of Asian origin; having a history of infertility; having a husband in social class III manual, IV, or V; and having a general practitioner not on the obstetric list. Risk factors known before the start of labour were gestational diabetes, urinary tract infection, pre-eclamptic toxaemia, antepartum haemorrhage, more than seven days of inpatient care, and no antenatal care. If a baby had a low birth weight this also increased the risk. Our adjustment for these confounding factors meant that any remaining differences in perinatal mortality rates were more likely to have been due to differences in the care received by patients.

This was a two stage study, in which a detailed casecontrol study of a subset of data is undertaken within the framework of a large, less detailed dataset. ${ }^{5}$ Such studies are particularly suited to subjects such as perinatal mortality rates; the comparatively rare perinatal deaths and their controls are nested within the framework of the large dataset of all notified births. We

TABLE I-Deliveries, perinatal deaths, and perinatal mortality rates per 1000 deliveries $(95 \%$ confidence intervals) according to place of booking and intended place of delivery at start of labour. Singleton deliveries in Leicestershire during 1978-87

\begin{tabular}{|c|c|c|c|c|c|}
\hline \multirow[b]{2}{*}{ Place of booking } & \multicolumn{4}{|c|}{ Intended place of delivery at start of labour } & \multirow[b]{2}{*}{ Total } \\
\hline & Hospital 1 & Hospital 2 & Hospital 3 & $\begin{array}{c}\text { General } \\
\text { practitioner } \\
\text { unit }\end{array}$ & \\
\hline \multicolumn{6}{|l|}{ Hospital 1: } \\
\hline Estimated No of deliveries & 45084 & 85 & & & 45169 \\
\hline No of perinatal deaths & 533 & 4 & & & 537 \\
\hline Crude perinatal mortality rate & $\begin{array}{c}11 \cdot 6 \\
(10 \cdot 6 \text { to } 12 \cdot 6)\end{array}$ & $\star$ & & & $\begin{array}{c}11 \cdot 7 \\
(10 \cdot 7 \text { to } 11 \cdot 7)\end{array}$ \\
\hline Adjusted perinatal mortality rate† & $\begin{array}{c}11 \cdot 2 \\
(10 \cdot 3 \text { to } 12 \cdot 2)\end{array}$ & 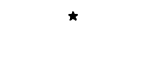 & & & $\begin{array}{c}11 \cdot 3 \\
(10 \cdot 3 \text { to } 12 \cdot 3)\end{array}$ \\
\hline \multicolumn{6}{|l|}{ Hospital 2: } \\
\hline Estimated No & 216 & 24833 & & & 25049 \\
\hline No of perinatal deaths & 5 & 240 & & & 245 \\
\hline Crude perinatal mortality rate & 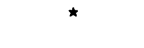 & $\begin{array}{c}9.9 \\
(8.6 \text { to } 11 \cdot 2)\end{array}$ & & & $\begin{array}{c}10 \cdot 0 \\
(8 \cdot 8 \text { to } 11 \cdot 3)\end{array}$ \\
\hline Adjusted perinatal mortality rate† & * & $\begin{array}{c}9 \cdot 0 \\
(7 \cdot 9 \text { to } 10 \cdot 1)\end{array}$ & & & $\begin{array}{c}9.2 \\
(8 \cdot 1 \text { to } 10 \cdot 4)\end{array}$ \\
\hline \multicolumn{6}{|l|}{ Hospital 3: } \\
\hline Estimated No of de & 863 & 341 & 13790 & $\ddagger$ & 14994 \\
\hline No of perinata & 10 & 7 & 118 & 2 & 137 \\
\hline Crude pe & \pm & * & $\begin{array}{c}9 \cdot 0 \\
(7 \cdot 4 \text { to } 10 \cdot 6)\end{array}$ & * & $\begin{array}{c}9.3 \\
(7.8 \text { to } 10.9)\end{array}$ \\
\hline Adjusted perinatal mortality rate & * & * & $\begin{array}{c}10 \cdot 0 \\
(8 \cdot 2 \text { to } 11 \cdot 8)\end{array}$ & ネ & $\begin{array}{c}10.1 \\
(8.4 \text { to } 11.8)\end{array}$ \\
\hline \multicolumn{6}{|l|}{ General practitioner unit: } \\
\hline Estimated No of deliveries & 7622 & 3413 & 666 & 17049 & 28750 \\
\hline No of perinatal deaths & 135 & 49 & 13 & 54 & 251 \\
\hline Crude perinatal mortality rate & $\begin{array}{c}17 \cdot 8 \\
(14 \cdot 8+0 \cdot 20 \cdot 8)\end{array}$ & $\begin{array}{c}14 \cdot 5 \\
(10 \cdot 4 \text { to } 18 \cdot 6)\end{array}$ & $\begin{array}{c}17 \cdot 9 \\
(6 \cdot 5+029 \cdot 3)\end{array}$ & $\begin{array}{c}3 \cdot 3 \\
(2 \cdot 4 \text { to } 4 \cdot 2)\end{array}$ & $\begin{array}{c}8 \cdot 8 \\
(7 \cdot 7 \text { to } 9 \cdot 9)\end{array}$ \\
\hline Adjusted perinatal mortality ratef & $\begin{array}{c}18 \cdot 8 \\
(15 \cdot 6 \text { to } 22 \cdot 0)\end{array}$ & $\begin{array}{c}15 \cdot 8 \\
(11 \cdot 4 \text { to } 20 \cdot 2)\end{array}$ & $\begin{array}{c}19 \cdot 7 \\
(7 \cdot 1 \text { to } 26 \cdot 8)\end{array}$ & $\begin{array}{c}3 \cdot 8 \\
\text { (2.8 to } 4 \cdot 8)\end{array}$ & $\begin{array}{c}9.6 \\
(8.4 \text { to } 10.8)\end{array}$ \\
\hline \multicolumn{6}{|l|}{ Total: } \\
\hline No of deliveries & 53929 & 28928 & 14456 & 17049 & 114362 \\
\hline No of perinatal deaths & 690 & 302 & 131 & 56 & 1179 \\
\hline Crude perinatal mortality rate & $\begin{array}{c}12.6 \\
(11.7 \text { to } 13.5)\end{array}$ & $\begin{array}{c}10 \cdot 6 \\
(9 \cdot 4 \text { to } 11 \cdot 8)\end{array}$ & $\begin{array}{c}9.4 \\
(7 \cdot 8 \text { to } 11 \cdot 0)\end{array}$ & $\begin{array}{c}3 \cdot 3 \\
(2 \cdot 4 \text { to } 4 \cdot 2)\end{array}$ & $\begin{array}{c}10.3 \\
(9.7 \text { to } 10.9)\end{array}$ \\
\hline Adjusted perinatal mortality rate & $\begin{array}{c}12.4 \\
(11.5 \text { to } 13.3)\end{array}$ & $\begin{array}{c}10 \cdot 1 \\
(9 \cdot 0 \text { to } 11 \cdot 2)\end{array}$ & $\begin{array}{c}10 \cdot 5 \\
(8 \cdot 7 \text { to } 12 \cdot 3)\end{array}$ & $\begin{array}{c}3.8 \\
(2.8 \text { to } 4.8)\end{array}$ & ND \\
\hline
\end{tabular}

Not calculated because of small numbers of cases.

tAdjusted for risk factors known at booking.

$\ddagger$ No estimation possible as no controls were originally booked in hospital 3 and delivered in general practitioner units. used a logistic regression method for analysing our two stage study that allowed for the control sample being stratified and corrected the estimates for differing sampling rates in different strata (the different hospitals). Although corrected estimates are easy to obtain, no software exists which correctly computes confidence intervals for the estimates of the regression coefficients. Here we present approximate $95 \%$ confidence intervals for the crude rates. The correction of the rates by logistic regression slightly increased the width of the confidence intervals, but this had little effect on our conclusions.

\section{CLASSIFICATION OF PERINATAL DEATH}

Wigglesworth described the difficulty of devising a classification of perinatal death to satisfy obstetricians, neonatologists, pathologists, and epidemiologists. ${ }^{6} \mathrm{His}$ classification allowed all perinatal deaths to be categorised whether or not necropsy had been undertaken. This review included deaths in more than 30 hospitals, most of which did not have paediatric pathology services. Our method of classification was derived from that of Wigglesworth but slightly differed from it. Using time of death in relation to delivery, gestation, and absence or presence of congenital abnormalities, we classified each death into one of four categories: congenital malformations; macerated stillbirths (prepartum stillbirths); asphyxia in labour (intrapartum stillbirths and early neonatal deaths at $\geqslant 38$ weeks' gestation); and immaturity (early neonatal deaths at $<38$ weeks' gestation).

\section{CLASSIFICATION OF HOSPITALS}

Women in Leicestershire used 30 consultant units and nine general practitioner units during the study. In this analysis hospitals 1 and 2 were the county's main consultant units, all the other consultant units were grouped together as hospital 3, and all the general practitioner units were grouped together. During the study all but one of the general practitioner units were closed.

\section{Results}

We estimate that $13206(12 \%)$ of the 114362 women were delivered at hospitals where they were not initially booked for delivery (table I). Referral to other hospitals was particularly common for women who were initially booked for delivery at general practitioner units: $11701(41 \%)$ of the 28750 women were delivered in consultant units. These 11701 women had the highest perinatal mortality rate of any group shown in table I (16.8/1000 deliveries). In contrast, the women who were booked at general practitioner units and delivered there had by far the lowest perinatal mortality rate $(3 \cdot 3 / 1000$ deliveries). Thus nearly four fifths of the perinatal deaths that occurred among women booked at a general practitioner unit did so in a consultant unit.

When the perinatal mortality rate was calculated on the basis of the hospital attended at the start of labour the crude perinatal mortality rate in hospital 1 (12.6/ 1000 deliveries) was a third higher than that in hospital $3(9 \cdot 4 / 1000$ deliveries). No estimates of perinatal mortality rates were made for the units where few referrals and subsequent perinatal deaths occurred.

Table II shows the perinatal mortality rates for each of the four categories of perinatal death among women who were booked for delivery at a general practitioner unit. The distribution of deaths in this group among the four categories was similar to the distribution of all perinatal deaths in the study. In contrast, macerated stillbirths were underrepresented in the stillbirths that occurred at general practitioner units while deaths due 
TABLE II-Perinatal mortality rates (95\% confidence intervals) for each category of perinatal death among women booked for delivery at general practitioner units. Singleton deliveries in Leicestershire during 1978-87

\begin{tabular}{|c|c|c|c|c|c|}
\hline \multirow[b]{2}{*}{ Category of perinatal death } & \multicolumn{4}{|c|}{ Place of delivery } & \multirow[b]{2}{*}{ Total } \\
\hline & Hospital 1 & Hospital 2 & Hospital 3 & $\begin{array}{c}\text { General } \\
\text { practitioner } \\
\text { unit }\end{array}$ & \\
\hline \multicolumn{6}{|l|}{ Congenital malformation: } \\
\hline Crude mortality rate & $\begin{array}{c}4 \cdot 6 \\
\text { (3.1 to } 6 \cdot 1)\end{array}$ & $\begin{array}{c}2.0 \\
(0.5 \text { to } 3.5)\end{array}$ & $\begin{array}{c}3 \cdot 6 \\
(0 \text { to } 7 \cdot 7)\end{array}$ & $\begin{array}{c}0.7 \\
(0.3 \text { to } 1.1)\end{array}$ & $\begin{array}{c}2 \cdot 0 \\
(1 \cdot 8 \text { to } 2 \cdot 2)\end{array}$ \\
\hline Adjusted mortality rate ${ }^{\star}$ & $\begin{array}{c}5.2 \\
(3.5 \text { to } 6.9)\end{array}$ & $\begin{array}{c}2 \cdot 3 \\
(0 \cdot 6 \text { to } 4 \cdot 0)\end{array}$ & $\begin{array}{c}3.7 \\
(0 \text { to } 7.9)\end{array}$ & $\begin{array}{c}0.8 \\
(0.4 \text { to } 1.2)\end{array}$ & $\begin{array}{c}2.2 \\
(1.9 \text { to } 2.5)\end{array}$ \\
\hline \multicolumn{6}{|l|}{ Macerated stillbirth: } \\
\hline Crude mortality rate & $\begin{array}{c}7.5 \\
(5.5 \text { to } 9.5)\end{array}$ & $\begin{array}{c}8 \cdot 3 \\
(5 \cdot 2 \text { to } 11 \cdot 4)\end{array}$ & $\begin{array}{c}11.4 \\
(3.5 \text { to } 19.3)\end{array}$ & $\begin{array}{c}0.7 \\
(0.3 \text { to } 1.1)\end{array}$ & $\begin{array}{c}3 \cdot 7 \\
(3 \cdot 4 \text { to } 4 \cdot 0)\end{array}$ \\
\hline Adjusted mortality rate & $\begin{array}{c}7 \cdot 7 \\
(5 \cdot 7 \text { to } 9 \cdot 7)\end{array}$ & $\begin{array}{c}9 \cdot 1 \\
(5 \cdot 7 \text { to } 12 \cdot 5)\end{array}$ & $\begin{array}{c}13 \cdot 6 \\
(4 \cdot 2 \text { to } 23 \cdot 0)\end{array}$ & $\begin{array}{c}0.8 \\
(0.4 \text { to } 1.2)\end{array}$ & $\begin{array}{c}3.9 \\
(3.5 \text { to } 4.3)\end{array}$ \\
\hline \multicolumn{6}{|l|}{ Asphyxia in labour: } \\
\hline Crude mortality rate & $\begin{array}{c}2 \cdot 1 \\
(1 \cdot 0 \text { to } 3 \cdot 2)\end{array}$ & $\begin{array}{c}1.9 \\
(0.4 \text { to } 3.4)\end{array}$ & $\dagger$ & $\begin{array}{c}1.0 \\
(0.5 \text { to } 1.5)\end{array}$ & $\begin{array}{c}1.4 \\
(1.2 \text { to } 1 \cdot 6)\end{array}$ \\
\hline Adjusted mortality rateł & $\begin{array}{c}2 \cdot 1 \\
(1.0 \text { to } 3 \cdot 2)\end{array}$ & $\begin{array}{c}2 \cdot 1 \\
(0.4 \text { to } 3 \cdot 8)\end{array}$ & $\dagger$ & $\begin{array}{c}1.3 \\
(0.7 \text { to } 1.9)\end{array}$ & $\begin{array}{c}1.6 \\
(1.4 \text { to } 1.8)\end{array}$ \\
\hline \multicolumn{6}{|l|}{ Immaturity: } \\
\hline Crude mortality rate & $\begin{array}{c}3.6 \\
(2.3 \text { to } 4.9)\end{array}$ & $\begin{array}{c}2 \cdot 4 \\
(0 \cdot 7 \text { to } 4 \cdot 1)\end{array}$ & $t$ & $\begin{array}{c}0.6 \\
(0.2 \text { to } 1.0)\end{array}$ & $\begin{array}{c}1.6 \\
(1.4 \text { to } 1.8)\end{array}$ \\
\hline Adjusted mortality rate $\oint$ & $\begin{array}{c}1.0 \\
(0.6 \text { to } 1.4)\end{array}$ & $\begin{array}{c}1.0 \\
(0.3 \text { to } 1.7)\end{array}$ & $t$ & $\begin{array}{c}0.8 \\
(0.3 \text { to } 1.3)\end{array}$ & $\begin{array}{c}0.9 \\
(0.8 \text { to } 1.0)\end{array}$ \\
\hline
\end{tabular}

*Adjusted for risk factors known at booking.

*Not calculated because of small numbers.

fAdjusted for risk factors known at booking and before start of labour.

SAdjusted for risk factors known at booking and before start of labour and for low birth weight.

TABLE III-Perinatal mortality rates (95\% confidence intervals) for each category of perinatal death according to place of delivery. Singleton deliveries in Leicestershire during 1978-87

\begin{tabular}{|c|c|c|c|c|c|}
\hline \multirow[b]{2}{*}{ Category of perinatal death } & \multicolumn{4}{|c|}{ Place of delivery } & \multirow[b]{2}{*}{ Total } \\
\hline & Hospital 1 & Hospital 2 & Hospital 3 & $\begin{array}{c}\text { General } \\
\text { practitioner } \\
\text { unit }\end{array}$ & \\
\hline \multicolumn{6}{|l|}{ Congenital malformation: } \\
\hline Crude mortality rate & $\begin{array}{c}3 \cdot 1 \\
(2 \cdot 6 \text { to } 3 \cdot 6)\end{array}$ & $\begin{array}{c}2 \cdot 0 \\
(1 \cdot 4 \text { to } 2 \cdot 6)\end{array}$ & $\begin{array}{c}2 \cdot 1 \\
(1 \cdot 3 \text { to } 2 \cdot 9)\end{array}$ & $\begin{array}{c}0.7 \\
(0.3 \text { to } 1.0)\end{array}$ & $\begin{array}{c}2 \cdot 3 \\
(2 \cdot 0 \text { to } 2 \cdot 6)\end{array}$ \\
\hline Adjusted mortality rate & $\begin{array}{c}3 \cdot 1 \\
(2 \cdot 6 \text { to } 3 \cdot 6)\end{array}$ & $\begin{array}{c}1.8 \\
(1.3 \text { to } 2.3)\end{array}$ & $\begin{array}{c}2.4 \\
(1.5 \text { to } 3 \cdot 3)\end{array}$ & $\begin{array}{c}0.8 \\
(0.4 \text { to } 1.2)\end{array}$ & \\
\hline \multicolumn{6}{|l|}{ Macerated stillbirth: } \\
\hline Crude mortality rate & $\begin{array}{c}5 \cdot 0 \\
(4 \cdot 3 \text { to } 5 \cdot 7)\end{array}$ & $\begin{array}{c}4.6 \\
(3.7 \text { to } 5.5)\end{array}$ & $\begin{array}{c}3.3 \\
(2.3 \text { to } 4 \cdot 3)\end{array}$ & $\begin{array}{c}0.7 \\
(0.3 \text { to } 1.0)\end{array}$ & $\begin{array}{c}4 \cdot 0 \\
\text { (3.6 to } 4 \cdot 4)\end{array}$ \\
\hline Adjusted mortality rate & $\begin{array}{c}4.9 \\
(4.2 \text { to } 5 \cdot 6)\end{array}$ & $\begin{array}{c}4 \cdot 4 \\
(3 \cdot 5 \text { to } 5 \cdot 3)\end{array}$ & $\begin{array}{c}3.8 \\
(2.5 \text { to } 5.0)\end{array}$ & $\begin{array}{c}0.8 \\
(0.4 \text { to } 1.2)\end{array}$ & \\
\hline \multicolumn{6}{|l|}{ Asphyxia in labour: } \\
\hline Crude mortality rate & $\begin{array}{c}1.5 \\
(1.1 \text { to } 1.9)\end{array}$ & $\begin{array}{c}1.9 \\
(1.4 \text { to } 2.5)\end{array}$ & $\begin{array}{c}1.6 \\
(0.9 \text { to } 2 \cdot 3)\end{array}$ & $\begin{array}{c}1.0 \\
(0.5 \text { to } 1.5)\end{array}$ & $\begin{array}{c}1.6 \\
(1.3 \text { to } 1.9)\end{array}$ \\
\hline Adjusted mortality ratef & $\begin{array}{c}1.4 \\
(1 \cdot 1 \text { to } 1 \cdot 7)\end{array}$ & $\begin{array}{c}1.8 \\
(1.3 \text { to } 2 \cdot 3)\end{array}$ & $\begin{array}{c}1.9 \\
(1 \cdot 1 \text { to } 2 \cdot 7)\end{array}$ & $\begin{array}{c}1.3 \\
(0.7 \text { to } 1.9)\end{array}$ & \\
\hline \multicolumn{6}{|l|}{ Immaturity: } \\
\hline Crude mortality rate & $\begin{array}{c}3 \cdot 1 \\
(2.6 \text { to } 3 \cdot 6)\end{array}$ & $\begin{array}{c}2.1 \\
(1.5 \text { to } 2.7)\end{array}$ & $\begin{array}{c}2.3 \\
(1.5 \text { to } 3.1)\end{array}$ & $\begin{array}{c}0.6 \\
(0.2 \text { to } 1.0)\end{array}$ & $\begin{array}{c}2 \cdot 4 \\
(2 \cdot 1 \text { to } 2 \cdot 7)\end{array}$ \\
\hline Adjusted mortality rate‡ & $\begin{array}{c}1.9 \\
(1.6 \text { to } 2.2)\end{array}$ & $\begin{array}{c}2.5 \\
(1.8 \text { to } 3.2)\end{array}$ & $\begin{array}{c}5 \cdot 7 \\
(3 \cdot 7 \text { to } 7 \cdot 7)\end{array}$ & $\begin{array}{c}0.8 \\
(0.3 \text { to } 1.3)\end{array}$ & \\
\hline
\end{tabular}

*Adjusted for risk factors known at booking

tAdjusted for risk factors known at booking and before start of labour

$\ddagger$ Adjusted for risk factors known at booking and before start of labour and for low birth weight.

to asphyxia in labour were overrepresented. This reflects the more predictable nature of macerated stillbirths and the less predictable nature of asphyxia in labour. Adjustment for risk factors made little difference to the mortality rates except when birth weight was included in the adjustment for the deaths due to immaturity.

Table III shows the perinatal mortality rates for each of the four categories of perinatal death for the four places of delivery. These data are equivalent to those produced by the registrar general. Hospital 1 , which had the highest overall perinatal mortality rate (table I), also had the highest perinatal mortality rates for congenital malformation and macerated stillbirth. These two categories, however, are only indirectly affected by obstetric management. Asphyxia in labour and immaturity are more directly affected by obstetric and paediatric management. For these categories hospital 1 had the lowest perinatal mortality rates among the consultant units after adjustment for risk factors. By far the greatest effect on the crude mortality rates was when mortality rates due to immaturity were adjusted for low birth rate.

\section{Discussion}

More than 100 years ago Florence Nightingale compared mortalities between maternity hospitals and suggested that differences in the construction of the hospitals might account for differences in mortality. ${ }^{7}$ More recently mortality in hospital has again become a subject of concern, ${ }^{8}$ as has the difficulty of comparing mortalities in hospitals. ${ }^{9}$ The problems of interpreting perinatal mortality rates have been described by Campbell and MacDonald Davies ${ }^{10}$ and Tew. ${ }^{11}$ Over the past 15 years perinatal mortality rates have more than halved while the social and political pressure to measure and interpret them has increased.

We have shown that in over 110000 deliveries there are only small, non-significant differences in perinatal mortality rates between hospitals when the place of booking is considered and that these are further reduced when adjustments are made to allow for the risk factors known at booking. Overall $12 \%$ of women were delivered at hospitals other than the one where they were initially booked. Such changes occurred most commonly when women were initially booked to deliver at general practitioner hospitals: $40 \%$ of them were delivered at a consultant unit. Perhaps not surprisingly, the women transferred to consultant care had the highest perinatal mortality rates. For $70 \%$ of such women, however, the outcome was not amenable to intervention as the baby died before labour or death was due to a congenital malformation. The transfer of these women from general practitioner care to hospital care accounts for much of the apparent mortality advantage of general practitioner units, a finding that contrasts with Tew's observations. ${ }^{11}$

Adjustment for risk factors known before the start of labour made little difference to perinatal mortality rates, but such differences that occurred were in the expected direction. For example, adjustment increased the low perinatal mortality rate for women who were delivered at a general practitioner unit and decreased the high rate in hospital 1, which had an accident and emergency department. The small effect of adjustment for case mix may not be the same throughout Britain. The two main city obstetric units in Leicestershire possibly care for women with differing risk profiles, so that the excess risks in one population are offset by different excess risks in the other. Adjustment for birth weight had the greatest effect on the perinatal mortality rates due to immaturity: the rate among women who were booked at general practitioner units and were delivered at hospital 1 fell from 3.6 to $1 \cdot 0$. This shows how important such adjustments can be for units that provide neonatal intensive care.

Perinatal mortality rates are affected by a broad range of biological, social, and medical factors. As Wigglesworth suggested, only perinatal deaths due to asphyxia in labour and immaturity directly reflect the effectiveness of medical care, and these categories accounted for only $16 \%$ and $23 \%$ of perinatal deaths, respectively, in this series-an average of 46 deaths a year from an average of over 11000 births occurring in several hospitals. In view of the factors discussed above it is most unwise to compare the effectiveness of hospital units by means of crude, unadjusted perinatal mortality rates.

We thank the midwives who helped with the interviewing; all the other staff in hospitals that provide maternity services to Leicestershire's mothers, both within and outside the county, for their help with this study; John Woods for computer support; and Pauline Payne for clerical and secretarial help. The study was supported by a grant from Leicestershire Health Authority.

1 Department of Health and Social Security. Report on confidential enquiries into 
Ieachs in England and Wales 1979-1981. London: HMSO, 1986. (Report on health and social subjects No 29. )

2 House of Commons Social Services Committee. First report on perinatal, neonatal and infant mortality. Session 1988/89. London: HMSO, 1988

3 Working group on the confidential enquiry into stillbirths and deaths in infancy. Report of the working group set up by the chief medical officer. London: infancy. Report of the working

4 Clarke M, Clayton DG, Mason ES, MacVicar J Asion mothers' risk of cerinatal death he same or different? A 10 year review of Leicest hisk perinatal deaths $B M 71988,297: 384-7$.

5 Cain KC, Breslow NE. Logistic regression analysis and efficient design for two stage studies. Am $\mathcal{F}$ Epidemiol 1988;128:1198-206.

6 Wigglesworth J. Monitoring perinatal mortality: a pathophysiologica approach. Lancet 1980;ii:684-6.
7 Nightingale F. Introductory notes on lying-in institutions. London: Longmans, Green, 1871.

8 Campling EA, Devlin HB, Hoile RW, Lunn JN. The repont of the National Confidential Enquiry into Perioperative Deaths 1990. London: National Confidential Enquiry into Perioperative Deaths, 1992.

9 Fink A, Yano EM, Brook RH. The condition of the literature on differences in hospital mortality. Med Care 1989;27:315-36.

10 Campbell R, MacDonald Davies I, Macfarlane A, Beral V. Home births in England and Wales, 1979: perinatal mortality according to intended place of delivery $B M 7$ 1984:289:721-4.

11 Tew M. Place of birth and perinatal mortality. $f R$ Coll Gen Pract 1985;35: $390-4$

(Accepted 7 fanuary 1993)
Department of Health, Richmond House, London SW1A 2NS

Morag Campbell Stern, senior registrar

\section{Department of}

Epidemiology and Public Health, University of Leicester, Leicester Royal Infirmary, PO Box 65, Leicester LE2 7LX

Carol Jagger, lecturer in medical statistics Michael Clarke, professor of epidemiology

Department of Psychiatry, University of Leicester Judith Anderson, honorary senior lecturer

\section{Department of}

Epidemiology and Public Health, University of Leicester

Catherine McGrother, senior lecturer

Department of Medicine for the Elderly, University of Leicester

Tim Battock, senior registrar

Social Services

Department, Leicestershire County

Council, Leicester

Cate McDonald, planning

officer, services for older people

Correspondence and requests for reprints to: Dr Jagger.

BMY 1993;306:827-30

\title{
Residential care for elderly people: a decade of change
}

\author{
Morag Campbell Stern, Carol Jagger, Michael Clarke, Judith Anderson, Catherine McGrother, \\ Tim Battock, Cate McDonald
}

Abstract

Objective-To determine the changes between 1979 and 1990 in demography and dependency levels in elderly people in residential care.

Design-Censuses of those aged 65 years and over in any type of residential care at midnight on 11 December 1979 and 27 November 1990.

Setting-Leicestershire District Health Authority (population 865133, 1991 census), coterminous with county and social services boundaries.

Main outcome measures-Age, sex, length of stay, and dependency levels (measured by activities of daily living).

Results-In 1990 (1979), 6079 (4678) elderly people were enumerated in 241 (133) establishments, a $30 \%$ increase in the numbers of elderly people in residential care and an $82 \%$ increase in the number of establishments between 1979 and 1990 . Dependency levels rose between 1979 and 1990 in all but the geriatric sector, the greatest increases being found in private residential homes where the largest percentage increase in the number of residents had occurred.

Conclusions-Dependency levels in residential care have risen substantially, particularly in the private sector, even beyond levels expected from the greater numbers of elderly people. With the impending move to community care, dependency levels are likely to rise further, and more appropriate staff training and medical input to homes will become necessary.

\section{Introduction}

Substantial changes in the provision of long term care for elderly people have taken place over the pas decade. Increased interest in using NHS geriatric beds for assessment and rehabilitation has led to increased turnover and shorter length of stay, ${ }^{1}$ with an expansion of acute beds and a decrease in the number of long stay beds. Government policy has been to close large mental hospitals and wherever possible to move to care in the community, ${ }^{2}$ with a resulting decrease in the number of psychiatric hospital beds. At the same time, local authorities have been subject to increasing financial constraints, resulting in the level of provision of accommodation by social services remaining static or even contracting slightly. ${ }^{3}$

The private residential sector, on the other hand, has expanded considerably, with greater numbers of both homes for elderly people and nursing homes. ${ }^{4}$ The reasons for this are a political philosophy of increasing private provision coupled with changes in the funding arrangements for those entering residential care, specifically the introduction of supplementary benefit payments to those unable to afford the fees at private homes. ${ }^{4}$ Entry then became based on financial rather than medical or social assessment, ${ }^{5}$ and in 1983 upper limits were set on supplementary benefit, resulting in a massive increase in the total national bill for supplementary benefits to people in private sector homesfrom $f 105 \mathrm{~m}$ in 1983 to $f 500 \mathrm{~m}$ by $1986 .{ }^{\circ}$ Concern that this uncontrolled expansion of the private sector had been siphoning off funds that might have been more cost effectively used in home based community care ${ }^{7}$ led to the government commissioning reviews of resource management and quality of care ${ }^{89}$ These formed the basis for the 1990 National Health Service and Community Care Act, the final phase of which is to be implemented in 1993. ${ }^{10}$

The first census of people over 65 in residential care in Leicestershire was undertaken in 1976, with a second in $1979 .{ }^{11-13}$ Given the changes over the previous decade, a further review of the size and distribution of the Leicestershire residential care sector was considered to be essential both to set an information baseline before the implementation of the National Health Service and Community Care Act and to document changes in the demography and levels of dependency of the residential care population. This paper presents comparisons of the residential care populations in 1979 and 1990.

\section{Methods}

The survey population comprised all those aged 65 years and over who were resident in any type of ward, hospital, home, or hostel provided by the NHS, local authority social services department, or private and voluntary agencies within Leicestershire at midnight on 27 November 1990. The time of year was chosen to be as close as possible to that of the 1979 census to ensure that seasonal mortality effects would not confound results. The census was confined to homes containing four or more residents registered (under the provision of the 1984 Registered Homes Act) with the health authority or the local authority for purely practical reasons. Homes with fewer than four residents are not, as yet, required to register with social services, and since no formal list of these homes exists, the size of this sector remains unknown.

Questionnaires were delivered to each establishment in the week before census night by members of the University of Leicester departments undertaking the survey, who explained the questionnaire to a senior staff member. The questionnaire, covering demographic details and levels of health and functioning, was completed by care staff for each person in their 